\title{
BEARING CAPACITY OF STRIP FOOTING ON REINFORCED LAYERED GRANULAR SOILS
}

\author{
Elif CICEK ${ }^{\mathrm{a}}$, Erol GULER ${ }^{\mathrm{b}}$ \\ ${ }^{a}$ Department of Civil Engineering, Ataturk University, 25240 Erzurum, Turkey \\ ${ }^{b}$ Department of Civil Engineering, Bogazici University, 34342 Istanbul, Turkey
}

Received 19 Jul 2012; accepted 12 Nov 2012

\begin{abstract}
In this study a limit equilibrium method is proposed to determine the bearing capacity of strip foundations on geosynthetic reinforced sand soils. A two-layered granular soil was foreseen to represent the loose in situ soil and the compacted fill above the reinforcement. First the modified bearing capacity factors $N_{q}$ and $N_{\gamma}$ were derived for the two layered granular reinforced soil. The bearing capacities were also calculated for different reinforcement geometries and soil properties using Finite Element analyses. The bearing capacities obtained from Finite Element and Limit Equilibrium analyses were compared, it was seen a good agreement. Therefore, it was concluded that the new limit equilibrium method proposed in this paper for reinforced two-layered soils can be successfully used in calculating the bearing capacities of geosynthetic reinforced soils.
\end{abstract}

Keywords: bearing capacity, reinforced soil, tensile force, layered soils, strip footing, finite elements.

\section{Introduction}

Geosynthetic reinforcement is used to increase the bearing capacity of foundation soils and to reduce differential settlements under surface foundations. As it is known, bearing capacity of reinforced foundation soil is affected by the position, size, stiffness and tensile strength of reinforcement and there is no common agreement upon a simple design method available to calculate the bearing capacity of a geosynthetic reinforced foundation. In this study, a simple method for determining the bearing capacity of a geosynthetic reinforced soil was developed. In order to determine the effect of the reinforcement in the foundation soil, a simple analysis technique developed by Ghazavi and Eghbali (2008) to calculate the bearing capacity of a two layered foundation soil was adapted. To validate the newly proposed limit equilibrium method, several cases were analyzed using a Finite Element Model and the results were compared.

\section{Summary of literature}

\subsection{Bearing capacity of reinforced foundations}

Many researchers have investigated the bearing capacity of geosynthetic reinforced foundation soils using experimental, analytical and numerical methods. Binquet and Lee (1975a) carried out one of the first experimental studies to analyze the bearing capacity of reinforced soils. After them a lot of researches implemented the experimental approach to understand the behavior of reinforced granular soils (Huang, Tatsuoka 1990; Yetimoglu et al. 1994; Adams, Collin 1997; Patra et al. 2006; Chen 2007; El Sawwaf, Nazir 2010; Tafreshi, Dawson 2010; Lavasan, Ghazavi 2012). Several researches used numerical method to determine the bearing capacity of reinforced foundation soils (Yamamoto, Otani 2002; Nogueira et al. 2008; Madhavi, Somwanshi 2009; Gu 2011; Abu-Farsakh et al. 2012). In the experimental and numerical studies the optimum vertical spacing of reinforcement, the maximum total depth of reinforced soil, the effective length of reinforcements and the optimum depth of the first reinforcement layer were investigated.

Analytical models for estimating the bearing capacities of foundations on reinforced soil have also been developed (Binquet, Lee 1975b; Wayne et al. 1998; Kumar, Saran 2003; Huang, Meng 1997; Michalowski 2004; Sharma et al. 2009; Dey 2010). Binquet and Lee $(1975 \mathrm{~b})$ reported the failure mechanism of strip footings on reinforced soil. They determined three failure mechanisms depending on the configuration and tensile force of reinforcement, namely: a) shear above reinforcements; b) tie pullout; and c) tie break. They calculated the tensile load on the reinforcement, as a function of the difference between the bearing capacities of reinforced and unreinforced soils. Huang and Tatsuoka (1990) conducted a series of plane strain model tests with a strip footing and measured the tensile forces in the reinforcement.

Corresponding author: Erol Guler

E-mail:eguler@boun.edu.tr 
They conducted tests with different reinforcement length, rigidity, arrangement and tensile strength. They used these measured reinforcement stresses to calculate the additional bearing capacity due to the reinforcement. Huang and Meng (1997) based their studies on two failure mechanisms, namely deep-footing and wide-slab mechanisms. They considered that the effect of reinforcement is to distribute the foundation load to a greater area. This phenomenon was called 'the wide slab effect' by the researchers. Regression analyses were performed to find a relationship between the factors that control the scheme of reinforcement and the effect of reinforcing on the loadspreading angle. Michalowski (2004) suggested determining the reinforcement force based on the geometry and the tensile stress of the reinforcement. However, they directly used tensile strength value as the tensile stress in the reinforcement. Sharma et al. (2009) also developed analytical solutions for bearing capacity of geogrid reinforced soils. They performed an experimental study with sand and silty clay soils. In their study, the tensile force was estimated with a formula based on the elastic settlement suggested by Schmertmann et al. (1978). For a given footing the settlement distribution in reinforced soil was assumed to be the same as that in unreinforced soil and the strain in the reinforcement were calculated based on the shape of the settlement bowl (Sharma et al. 2009). Dey (2010) made a critical evaluation of two different bearing capacity theories of reinforced foundation beds. An enhanced data-set has been used to carry out a refined linear and nonlinear multivariable regression analysis. It was found that the relative depth, number of layers of reinforcement and the angle of internal friction of soil significantly influence the sensitivity of the system.

\subsection{Bearing capacity based on Coulomb theory}

In this paper the Coulomb failure mechanism technique was adapted to determine the bearing capacity of geosynthetic reinforced soil. The Coulomb failure mechanism was proposed by Lambe and Whitman (1969) to model the failure of soil under surface foundations. This theory is based on the fact that the soil underneath the foundation tends to expand and hence is in an active state. The soil expanding below the foundation tries to compress the soil outside of the foundation and therefore the soil outside the footing is considered to be in a passive state. Richards et al. (1993) adapted this technique and added to the formulation the effect of shear stresses that develop on the vertical plane that separates the active and passive zones. They adapted this modified Coulomb method to calculate the seismic bearing capacities of footings. Ghazavi and Eghbali (2008) also took the simple Coulomb method proposed by Lambe and Whitman (1969) and adapted it to a two layered soil. They checked the results obtained by using the Coulomb approach with the results obtained from Finite Element analyses. Ghazavi and Eghbali (2008) concluded that the results obtained from the Finite Element analysis matched very well with the results obtained from the Coulomb formulation.

\subsection{Direction of geosynthetic reinforcement in failure zone}

Michalowski (1998) stated that as failure occurs, the direction of a flexible reinforcement will change and try to align itself with the failure plane. So it is assumed that the direction of the tensile force will have the same direction as the failure plane. Michalowski (1998) stated further that failure normally occurs along a band and therefore the position of the reinforcement just before failure depends not only on the direction of the failure plane but also on the width of the shear zone.

\section{Model for geosynthetic reinforced foundations}

When a foundation soil is reinforced using geosynthetic reinforcement, the reinforcement is always covered with a soil layer. Therefore, in general there are two soil layers below the foundation, namely the natural soil and fill soil. Therefore, the limit equilibrium approach which allows the calculation of bearing capacity of a two layered soil proposed by Ghazavi and Eghbali (2008) was seen as a good tool to analyze the reinforced foundation problem. Since the soil above the reinforcement will be compacted properly, we considered the natural soil to be less dense than the fill soil. The literature generally reported that the effect of reinforcement changes with increasing distance of the reinforcement from the base of the footing. Many researchers investigated the optimum location of the top reinforcement layer. This value was changed between 0.25 and 0.75 . Therefore, in our model it is assumed that the reinforcement is laid directly on the loose soil, namely as far away from the footing as possible.

Although the literature suggest that it is beneficial to extend the reinforcement outside the footprint of the foundation, construction restraints may not allow this and this will lead to the condition that the reinforcement can be placed only as wide as the foundation itself. Therefore, two extreme models were considered in this study: a) the length of the geosynthetic reinforcement is just equal to the width of the foundation; and b) a very long reinforcement.

The failure surfaces were assumed as proposed by Ghazavi and Eghbali (2008) and given in Figure 1 for a reinforced two-layered soil. In Figure 1, the line KLM represents the failure line of the active zone and line MPR line represents the failure line in the passive zone according to the Coulomb failure mechanism. Here, $q$ is the surcharge load applied to the soil outside of the foundation. $h_{1}$ is the thickness of the fill layer and at the same time, the distance between the base of the foundation and the reinforcement. For the system to be in equilibrium for an unreinforced soil, the active and passive forces must be equal to each other. However, due to the addition of the reinforcement, the tensile load on the reinforcement also contributes to the resisting forces and must be considered in the equilibrium equation.

The free body diagrams of the active and passive zones for both soil layers and the tensile force within the 


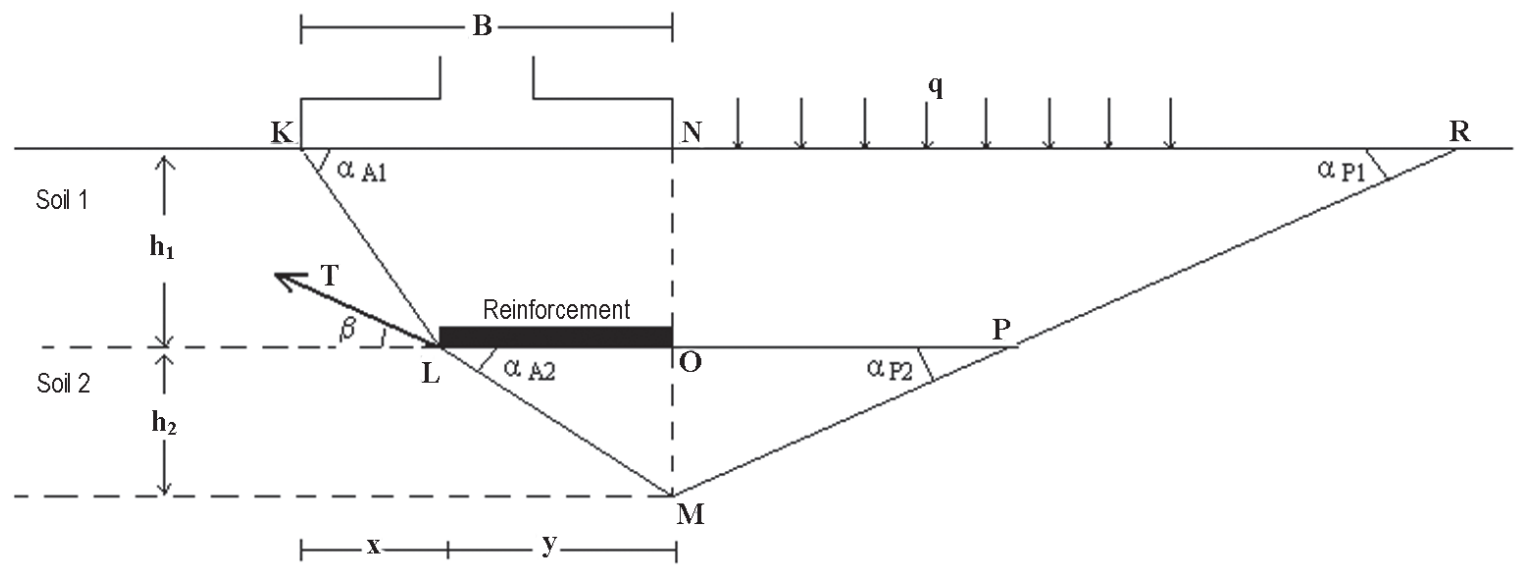

Fig. 1. Simplified slip area with Coulomb wedges and geosynthetic reinforcement

reinforcement are shown in Figure 2. The variables used in Figure 2 are: $\alpha_{A i}$ - angle of slip surface in the active zone; $\phi_{i}$ - internal friction angle; $\gamma_{i}$ - unit weight of the soil layers; $\delta_{i}$-friction angle along surface between active and passive zones; $K_{a}, K_{p}$-coefficients of active and passive pressures; $h_{1}$ - thickness of the fill layer; $h_{2}-$ the height of the failing soil in the second layer; $T$ - tensile force in the reinforcement; $\beta$ - angle between the tensile force and horizontal plane.
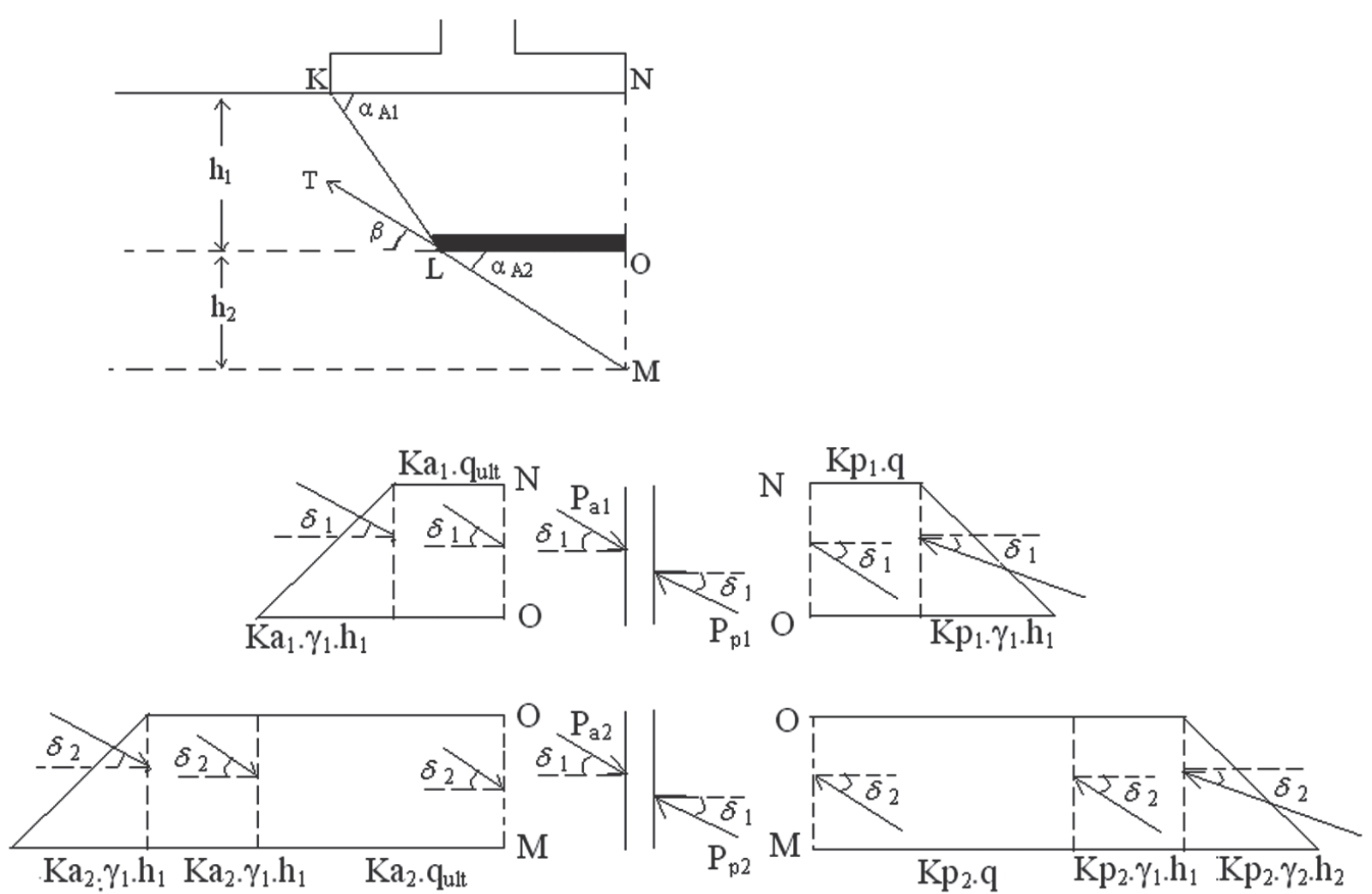

Fig. 2. Coulomb mechanism for reinforced two-layered soil 


$$
h_{2}=\left(B-h_{1} \cot \alpha_{A 1}\right) \tan \alpha_{A 2} .
$$

The active and passive earth pressure coefficient for each soil layer is calculated as follows (Ghazavi, Eghbali 2008):

$$
\begin{aligned}
& K_{a i}=\frac{\cos ^{2} \phi}{\left(\cos \delta_{i}\left[1+\sqrt{\sin \left(\varphi_{i}+\delta_{i}\right) \sin \varphi_{i} / \cos \delta_{i}}\right]^{2}\right)} \\
& K_{p i}=\frac{\cos ^{2} \phi}{\left(\cos \delta_{i}\left[1-\sqrt{\sin \left(\varphi_{i}+\delta_{i}\right) \sin \varphi_{i} / \cos \delta_{i}}\right]^{2}\right)} .
\end{aligned}
$$

The theoretical base of Eqns (1), (3) and (4) is Coulomb earth pressure theory. Resultants of active and passive earth pressures for each layer are defined as follows:

$$
\begin{gathered}
P_{a 1}=K_{a 1}\left(q_{u l t} h_{1}+0.5 \gamma_{1} h_{1}^{2}\right) ; \\
P_{a 2}=K_{a 2}\left(q_{u l t} h_{2}+\gamma_{1} h_{1} h_{2}+0.5 \gamma_{2} h_{2}^{2}\right) ; \\
P_{p 1}=K_{p 1}\left(q h_{1}+0.5 \gamma_{1} h_{1}^{2}\right) ; \\
P_{p 2}=K_{p 2}\left(0.5 \gamma_{2} h_{2}^{2}+\gamma_{1} h_{1} h_{2}+q h_{2}\right) .
\end{gathered}
$$

The horizontal component of the tensile force $T_{f}$ depends on the angle of the shear plane and the width of the shear band as explained above and the rigidity of the reinforcement used. The extreme values for flexible and rigid reinforcement respectively can be given as follows:

$$
\left(T_{f}\right)_{\min }=T^{*} \cos \alpha_{A 2} ; \quad\left(T_{f}\right)_{\max }=T .
$$

The total driving force is calculated as follows:

$$
P_{a h}=P_{a 1} \cos \delta_{1}+P_{a 2} \cos \delta_{2} .
$$

The total resisting force therefore can be determined as follows:

$$
P_{p h}=P_{p 1} \cos \delta_{1}+P_{p 2} \cos \delta_{2}+T \cos \beta .
$$

The bearing capacity of a strip footing on unreinforced cohesionless soil, $q_{u l t}$, is computed by Terzaghi (1943) using the following equation:

$$
q_{u l t}=q N_{q}+0.5 B \gamma N_{\gamma} .
$$

Ghazavi and Eghbali (2008) had expressed the bearing capacity of a two layered soil with the help of modified bearing capacity factors. This formulation was further developed in this paper for a geosynthetic reinforced soil. The modified $N_{q}$ and $N_{\gamma}$ values can be determined as derived below for two different assumptions, namely the case of "Weightless Soil" and the case of "No Surcharge". These are determined by applying the super position principle in subsequent section.

\subsection{State I: Weightless soil $\left(q \neq 0, \gamma_{1}=\gamma_{2}=0\right)$}

In this case the contribution of the soil weight on the bearing capacity is neglected. With this assumption the value of $\mathrm{N}_{q}$ will be calculated. For this purpose Eqns (5) and (6) are combined for weightless soil condition and Eqn (13) is obtained:

$$
P_{a h(\gamma=0)}=q_{u l t}\left(K_{a 1} h_{1} \cos \delta_{1}+K_{a 2} h_{2} \cos \delta_{2}\right) .
$$

Eqn (11) is modified to reflect the assumption of the weightless soil and the total passive earth pressure can be expressed as given in Eqn (14):

$$
P_{p h(\gamma=0)}=q\left(K_{p 1} h_{1} \cos \delta_{1}+K_{p 2} h_{2} \cos \delta_{2}\right)+T \cos \beta .
$$

Eqn (15) is obtained from the equilibrium of horizontal forces. Eqn (16) gives the Terzaghi bearing capacity equation for a weightless soil. When Eqns (15) and (16) are combined, the value of $N_{q}$ can be obtained as given by Eqn (17):

$$
\begin{gathered}
q_{u l t(\gamma=0)}=\frac{\left(q\left(K_{p 1} h_{1} \cos \delta_{1}+K_{p 2} h_{2} \cos \delta_{2}\right)+T \cos \beta\right)}{\left(K_{a 1} h_{1} \cos \delta_{1}+K_{a 2} h_{2} \cos \delta_{2}\right)} ; \\
q_{u l t}=q \cdot N_{q} \\
N_{q}=\left[\frac{K_{p 1} h_{1} \cos \delta_{1}+K_{p 2} h_{2} \cos \delta_{2}}{K_{a 1} h_{1} \cos \delta_{1}+K_{a 2} h_{2} \cos \delta_{2}}\right]+ \\
{\left[\frac{T \cos \beta}{q\left(K_{a 1} h_{1} \cos \delta_{1}+K_{a 2} h_{2} \cos \delta_{2}\right)}\right]}
\end{gathered}
$$

\subsection{State II: No surcharge $\left(q=0, \gamma_{1}, \gamma_{2} \neq 0\right)$}

In this case the formulation is derived by including the effect of the weight of the soil. However, this time the surcharge load in the surrounding soil is not considered in the formulation. The earth pressures in this case are given by Eqns (18) and (19):

$$
\begin{gathered}
P_{a h(q=0)}=q_{u l t}\left(K_{a} h_{1} \cos \delta_{1}+K_{a 2} h_{2} \cos \delta_{2}\right)+ \\
0.5 K_{a 1} \gamma_{1} h_{1}^{2} \cos \delta_{1}+K_{a 2} \cos \delta_{2}\left(\gamma_{1} h_{1} h_{2}+0.5 \gamma_{2} h_{2}^{2}\right) ; \\
P_{p h(q=0)}=0.5 K_{p 1} \gamma_{1} h_{1}^{2} \cos \delta_{1}+ \\
K_{p 2} \cos \delta_{2}\left(0.5 \gamma_{2} h_{2}^{2}+\gamma_{1} h_{1} h_{2}\right)+T \cdot \cos \beta
\end{gathered}
$$

For the purposes of simplicity, a dimensionless parameter $X$ is defined as proposed by Ghazavi and Eghbali (2008):

$$
X=h_{2} / h_{1}=\left(B \cdot \tan \alpha_{A 2} / h_{1}\right)-\left(\tan \alpha_{A 2} / \tan \alpha_{A 1}\right) .
$$

As seen in Figure 2, we have the horizontal active and passive pressures on the right and left sides of the line NOM and the tensile force in the reinforcement. Considering the equilibrium of horizontal forces, Eqn (21) is obtained: 


$$
\begin{aligned}
& {\left[0,5 \gamma_{1} \cos \delta_{1}\left(K_{p 1}-K_{a 1}\right)+\cos \delta_{2}\left(0,5 \gamma_{2} X^{2}+\right.\right.} \\
& q_{u l t(q=0)}=\frac{\left.\left.\gamma_{1} X\right)\left(K_{p 2}-K_{a 2}\right)\right] h_{1}+\frac{T \cos \beta}{h_{1}}}{\left(K_{a 1} \cos \delta_{1}+K_{a 2} X \cos \delta_{2}\right)} .
\end{aligned}
$$

The Terzaghi bearing capacity for a granular soil with zero cohesion and no surcharge load outside the footing is given as:

$$
q_{u l t}=0.5 B \gamma N_{\gamma}
$$

The value of $N \gamma$ can be determined by combining Eqns (21) and (22). To do that, a parameter is defined as the equivalent unit weight $(\bar{\gamma})$ showing the proportion of each layer in the rupture zone as originally proposed by Ghazavi and Eghbali (2008):

$$
\bar{\gamma}=\left(A_{1} \gamma_{1}+A_{2} \gamma_{2}\right) /\left(A_{1}+A_{2}\right),
$$

where $A_{1}$ and $A_{2}$ are the effective area of each layer in rupture zone and therefore are a function of $h_{1}$ and $h_{2}$. So $\bar{\gamma}$ can be determined as:

$$
\bar{\gamma}=\left(\frac{\mathrm{X}^{2} \gamma_{2}+\left(\mathrm{X}\left(\mathrm{B} / \mathrm{h}_{1}\right) \tan \alpha_{A 2}\right) \gamma_{1}}{\mathrm{X}^{2}+\left(\mathrm{X}\left(\mathrm{B} / \mathrm{h}_{1}\right) \tan \alpha_{A 2}\right)}\right)
$$

Thus $N_{\gamma}$ can be expressed as in Eqn (25):

$N_{\gamma}=\frac{\left[\begin{array}{r}0.5 \gamma_{1} \cos \delta_{1}\left(K_{p 1}-K_{a 1}\right)+\cos \delta_{2} \\ \left(0.5 \gamma_{2} \mathrm{X}^{2}+\gamma_{1} \mathrm{X}\right)\left(K_{p 2}-K_{a 2}\right)\end{array}\right] h_{1}+\frac{T \cos \beta}{h_{1}}}{0.5 \mathrm{~B} \bar{\gamma}\left(K_{a 1} \cos \delta_{1}+K_{a 2} \mathrm{X} \cos \delta_{2}\right)}$.

\section{Numerical analysis}

To verify the above derived formulation, Finite Element analyses were conducted. The software Plaxis V8 was chosen for these analyses. A plane strain model using triangular elements with 15 nodes was utilized and the Mohr-Coulomb Model was used to model the soil behavior. The parameters were chosen to be the same as given in the solutions of Ghazavi and Eghbali (2008), in order to be able to compare results of this study with their results. The width of the strip foundation (B) was chosen as 1,2 and $3 \mathrm{~m}$ and the surcharge load $q$ outside the footing was taken as $10 \mathrm{kN} / \mathrm{m}^{2}, 17.5 \mathrm{kN} / \mathrm{m}^{2}$, and $25 \mathrm{kN} / \mathrm{m}^{2}$, respectively. The footing thickness was $0.143 \mathrm{~m}$ and placed directly on the surface without any embedment. The footing's axial stiffness per unit width was chosen as $5 \times 10^{6} \mathrm{kN} / \mathrm{m}$ and it was modeled as an elastic material. In the Finite Element analyses the load applied on the footing is increased in equal steps until failure occurred. The reinforcement used was a geosynthetic reinforcement and its axial stiffness per unit width was selected as $\mathrm{J}=2,000 \mathrm{kN} / \mathrm{m}$ to represent an average geogrid (El Sawwaf 2007). The reinforcement width (L) was selected as B and 20B. It was modeled as a linear elastic material. In the analyses, no specific interaction model between soil and reinforcement was used.

The thickness of the first soil layer which is at the same time the depth of the reinforcement was normalized by dividing it to the width of the footing. Three different $h_{1} / \mathrm{B}$ values $(0.25,0.50$ and 0.75$)$ were selected. In limit equilibrium calculations, the value of $\delta$ usually ranges between $0.35 \phi$ and $0.45 \phi$ (Ghazavi, Eghbali 2008). Table 1 shows the soil properties used in the analyses. These properties were taken same as values given by Ghazavi and Eghbali (2008) to be able to compare and verify the unreinforced results. Since the system is symmetric, only half of the model was analyzed. The mesh size was chosen as fine and the first layer was chosen to be even finer. The horizontal and vertical distances from the center of the footing to the respective model boundaries were chosen as 10B in each analysis. In this paper, two different soil combinations were investigated. The friction angle of the fill (top) sand layer is $\phi_{1}$ and the friction angle of the natural (bottom) sand is $\phi_{2}$. In the first case the internal friction angle values were chosen as $\phi_{1}=34^{\circ}$ and $\phi_{2}=31^{\circ}$. In the second case they were taken as $\phi_{1}=39^{\circ}$ and $\phi_{2}=36^{\circ}$.

To calculate the bearing capacity with the limit equilibrium analysis proposed in this study, the activated tensile force in the reinforcement must be known. Therefore, the tensile forces in the reinforcement were determined using the Finite Element analysis and were put into the new limit equilibrium equation and the bearing capacities of the reinforced two-layered soil were calculated. In this calculation the new developed limit equilibrium coefficients $N_{\gamma}$ and $N_{q}$ were used. Table 2 shows the bearing capacity and maximum reinforcement tensile forces obtained from the Finite Element analyses. The results obtained from limit analysis are shown in Table 3. The symbols used in these Tables are as follows: $q_{u}$ is the

\begin{tabular}{|c|c|c|c|c|c|}
\hline 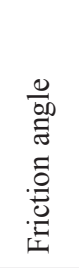 & 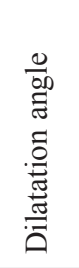 & 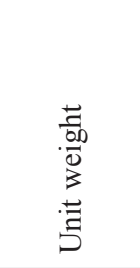 & $\begin{array}{l}\tilde{\theta} \\
\frac{0}{\Xi} \\
0 \\
\Xi \\
\Xi \\
00 \\
\Xi \\
0\end{array}$ & 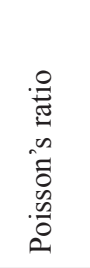 & 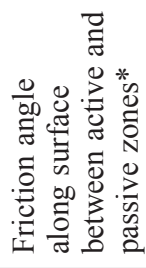 \\
\hline$\phi_{\mathrm{i}}\left(^{\circ}\right)$ & $\psi\left({ }^{\circ}\right)$ & $\gamma\left(\mathrm{kN} / \mathrm{m}^{2}\right)$ & $\mathrm{E}\left(\mathrm{kN} / \mathrm{m}^{2}\right)$ & $v$ & $\delta_{\mathrm{i}}\left({ }^{\circ}\right)^{*}$ \\
\hline 31 & 4.2 & 19.3 & 20 & 0.327 & 12 \\
\hline 34 & 6.4 & 20.1 & 27.5 & 0.306 & 14 \\
\hline 36 & 8 & 20.5 & 35 & 0.291 & 15 \\
\hline 39 & 10 & 20.9 & 50 & 0.27 & 17 \\
\hline
\end{tabular}
ultimate bearing capacity of unreinforced soil, $q_{1}$ is the bearing capacity of reinforced soil for $\mathrm{L}=\mathrm{B}, q_{2}$ is the bear-

Table 1. The properties of soils in the analyses (Ghazavi, Eghbali 2008)

*It has been stated by Ghazavi and Eghbali (2008) that for $30<\phi$ $<45$, the value of $\delta$ ranges between $0.35 \phi<\delta<0.45 \phi$ linearly. 
ing capacity of reinforced soil for $\mathrm{L}=20 \mathrm{~B}, T_{1}$ is the max tensile load in reinforcement for $\mathrm{L}=\mathrm{B}$ and $T_{2}$ is the max tensile load in reinforcement for $\mathrm{L}=20 \mathrm{~B}$. In Table 3 results of limit equilibrium analyses are displayed, where maximum tensile loads of reinforcement are taken as $T_{f}=T$ and $T_{f}=T \cos \alpha_{A 2}$.

From the obtained results it was seen that the tensile forces calculated by the finite element analyses are individually between the values given in Table 3 (where $T_{f}=T$ and $T_{f}=T \cos \alpha_{A 2}$ ). This is in good agreement with the assumption of Michalowski (1998) which states that failure occurs along a shear band and therefore the inclination of the reinforcement along the failure plane is not completely in alignment with the shear surface. The same calculations were done for the second model where the loose soil has an internal friction angle of $\phi=36^{\circ}$ and the fill soil is assumed to have an internal friction angle of $\phi=39^{\circ}$. The results for the second model are shown in Tables 4 and 5.

Table 2. Bearing capacity and maximum tensile forces of reinforcements obtained from $\operatorname{FEM}\left(\phi=34^{\circ} \text { on } \phi=31^{\circ}\right)^{*}$

\begin{tabular}{|c|c|c|c|c|c|c|c|}
\hline B & $h_{1} / \mathrm{B}$ & $h_{1}$ & $q_{\mathrm{u}^{*}}$ & $q_{1}$ & $q_{2}$ & $T_{1}$ & $T_{2}$ \\
\hline (m) & & (m) & $(\mathrm{kPa})$ & $(\mathrm{kPa})$ & $(\mathrm{kPa})$ & $(\mathrm{kN} / \mathrm{m})$ & $(\mathrm{kN} / \mathrm{m})$ \\
\hline 1 & 0.25 & 0.25 & 491 & 541 & 617 & 21.1 & 57.0 \\
\hline 1 & 0.5 & 0.5 & 526 & 635 & 687 & 63.6 & 74.6 \\
\hline 1 & 0.75 & 0.75 & 578 & 732 & 768 & 73.4 & 81.4 \\
\hline 2 & 0.25 & 0.5 & 879 & 989 & 1047 & 70.8 & 90.8 \\
\hline 2 & 0.5 & 1 & 910 & 1055 & 1115 & 102 & 125 \\
\hline 2 & 0.75 & 1.5 & 1001 & 1232 & 1283 & 141 & 161 \\
\hline 3 & 0.25 & 0.75 & 1086 & 1160 & 1216 & 104 & 136 \\
\hline 3 & 0.5 & 1.5 & 1133 & 1286 & 1305 & 172 & 197 \\
\hline 3 & 0.75 & 2.25 & 1203 & 1405 & 1486 & 219 & 231 \\
\hline
\end{tabular}

Table 3. Bearing capacity obtained from the new Limit equilibrium method $\left(\phi=34^{\circ}\right.$ on $\left.\phi=31^{\circ}\right)$

\begin{tabular}{cccccccc}
\hline \multicolumn{1}{c}{$T_{\mathrm{f}}=T$} & \multicolumn{3}{c}{$T_{\mathrm{f}}=T \cos \alpha_{\mathrm{A} 2}$} \\
\hline $\mathrm{y}$ & \multirow{2}{*}{$h_{1} / \mathrm{B}$} & $h_{1}$ & $q_{\mathrm{u}}$ & $q_{1}$ & $q_{2}$ & $\mathrm{q}_{1}$ & $\mathrm{q}_{2}$ \\
\cline { 3 - 8 }$(\mathrm{m})$ & & $(\mathrm{m})$ & $(\mathrm{kPa})$ & $(\mathrm{kPa})$ & $(\mathrm{kPa})$ & $(\mathrm{kPa})$ & $(\mathrm{kPa})$ \\
\hline 1 & 0.25 & 0.25 & 411 & 503 & 661 & 460 & 543 \\
\hline 1 & 0.5 & 0.5 & 435 & 717 & 766 & 585 & 610 \\
\hline 1 & 0.75 & 0.75 & 463 & 792 & 828 & 637 & 656 \\
\hline 2 & 0.25 & 0.5 & 780 & 935 & 979 & 862 & 885 \\
\hline 2 & 0.5 & 1 & 826 & 1052 & 1103 & 946 & 973 \\
\hline 2 & 0.75 & 1.5 & 880 & 1194 & 1240 & 1046 & 1070 \\
\hline 3 & 0.25 & 0.75 & 1150 & 1301 & 1348 & 1229 & 1254 \\
\hline 3 & 0.5 & 1.5 & 1217 & 1471 & 1508 & 1352 & 1371 \\
\hline 3 & 0.75 & 2.25 & 1296 & 1623 & 1641 & 1469 & 1478 \\
\hline & & & & & & &
\end{tabular}

Figure 3 shows the reinforcement tensile load distributions for the models with $\mathrm{B} / 2=0.5 \mathrm{~m} ; h_{1}=0.75 \mathrm{~m}$; $\phi_{1}=39^{\circ}$ on $\phi_{2}=36^{\circ}$. It is seen that no tensile force in the reinforcement developed beyond a distance of $3 \mathrm{~B}$ outside the foundation. Similar observations were made for other configurations as well.

These calculations show that if the reinforcement force can be known, the bearing capacity of a reinforced foundation can be directly calculated by the limit equilibrium formulation proposed. Therefore, an attempt was made to express the tensile force in the reinforcement as a function of the geometry and soil properties. The tensile forces obtained from the Finite Element analysis results, were evaluated with a multiple linear regression analysis. The comparison of bearing capacity values between Finite Element Method (FEM) and new Limit Equilibrium Method (LEM) can be seen as in Figures 4 and 5 . Figure 4 shows the bearing capacity values of first case $\left(\mathrm{B}=2 \mathrm{~m}, \mathrm{~L}=\mathrm{B}\right.$ and $\phi_{1}=34^{\circ}$ on $\left.\phi_{2}=31^{\circ}\right)$. Figure 5 is for second case $\left(\mathrm{B}=2, \mathrm{~L}=\mathrm{B}\right.$ and $\phi_{1}=39^{\circ}$ on $\phi_{2}=36^{\circ}$ ). In these Figures, reinforcement tensile stress was taken as $T$.

Table 4. Bearing capacity and maximum tensile forces of reinforcements obtained from $\operatorname{FEM}\left(\phi=39^{\circ}\right.$ on $\left.\phi=36^{\circ}\right)$

\begin{tabular}{cccccccc}
\hline \multicolumn{1}{c}{$\mathrm{B}$} & \multirow{2}{*}{$h_{1} / \mathrm{B}$} & $h_{1}$ & $q_{\mathrm{u}}$ & $q_{1}$ & $q_{2}$ & $T_{1}$ & $T_{2}$ \\
\cline { 1 - 7 } & & $(\mathrm{m})$ & $(\mathrm{kPa})$ & $(\mathrm{kPa})$ & $(\mathrm{kPa})$ & $(\mathrm{kN} / \mathrm{m})$ & $(\mathrm{kN} / \mathrm{m})$ \\
\hline 1 & 0.25 & 0.25 & 953 & 981 & 1153 & 30.0 & 62.1 \\
\hline 1 & 0.5 & 0.5 & 998 & 1192 & 1269 & 68.4 & 78.7 \\
\hline 1 & 0.75 & 0.75 & 1109 & 1244 & 1327 & 75.0 & 92.8 \\
\hline 2 & 0.25 & 0.5 & 1808 & 1958 & 2067 & 97.4 & 128 \\
\hline 2 & 0.5 & 1 & 1887 & 1994 & 2059 & 124 & 148 \\
\hline 2 & 0.75 & 1.5 & 2043 & 2252 & 2326 & 137 & 154 \\
\hline 3 & 0.25 & 0.75 & 2543 & 2723 & 2849 & 184 & 215 \\
\hline 3 & 0.5 & 1.5 & 2674 & 2946 & 3035 & 218 & 259 \\
\hline 3 & 0.75 & 2.25 & 2824 & 2999 & 3110 & 223 & 274 \\
\hline
\end{tabular}

Table 5. Bearing capacity obtained from the new Limit Equilibrium Method $\left(\phi=39^{\circ}\right.$ on $\left.\phi=36^{\circ}\right)$

\begin{tabular}{|c|c|c|c|c|c|c|c|}
\hline \multirow{3}{*}{$\frac{B}{(m)}$} & \multirow{3}{*}{$h_{1} / \mathrm{B}$} & \multirow{3}{*}{$\frac{h_{1}}{(\mathrm{~m})}$} & \multicolumn{3}{|c|}{$T_{\mathrm{f}}=T$} & \multicolumn{2}{|c|}{$T_{\mathrm{f}}=T \cos \alpha_{\mathrm{A} 2}$} \\
\hline & & & $q_{\mathrm{u}}$ & $q_{1}$ & $q_{2}$ & $q_{1}$ & $q_{2}$ \\
\hline & & & $(\mathrm{kPa})$ & $(\mathrm{kPa})$ & $(\mathrm{kPa})$ & $(\mathrm{kPa})$ & $(\mathrm{kPa})$ \\
\hline 1 & 0.25 & 0.25 & 846 & 994 & 1152 & 919 & 996 \\
\hline 1 & 0.5 & 0.5 & 893 & 1232 & 1284 & 1059 & 1084 \\
\hline 1 & 0.75 & 0.75 & 947 & 1323 & 1413 & 1131 & 1175 \\
\hline 2 & 0.25 & 0.5 & 1615 & 1855 & 1931 & 1732 & 1769 \\
\hline 2 & 0.5 & 1 & 1703 & 2013 & 2070 & 1855 & 1883 \\
\hline 2 & 0.75 & 1.5 & 1806 & 2152 & 2193 & 1975 & 1996 \\
\hline 3 & 0.25 & 0.75 & 2383 & 2686 & 2736 & 2532 & 2556 \\
\hline 3 & 0.5 & 1.5 & 2514 & 2875 & 2943 & 2690 & 2724 \\
\hline 3 & 0.75 & 2.25 & 2666 & 3040 & 3125 & 2849 & 2891 \\
\hline
\end{tabular}




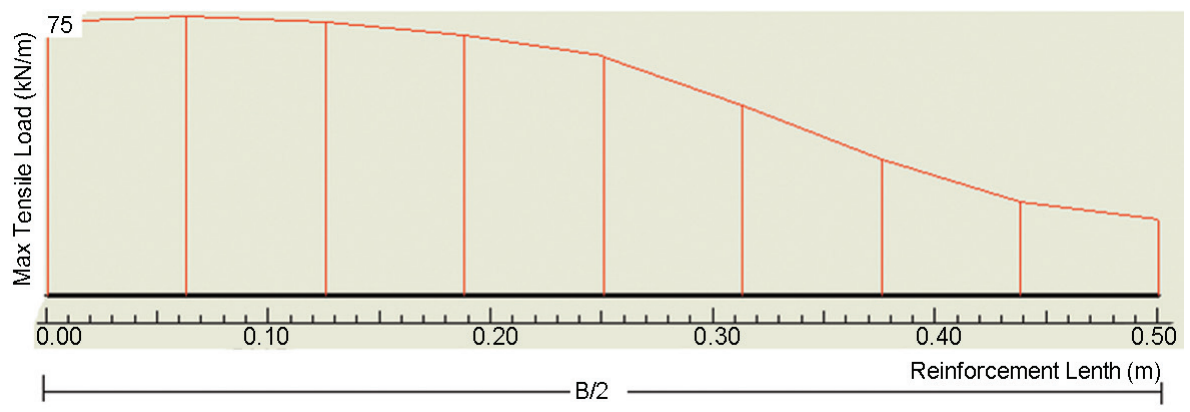

a)

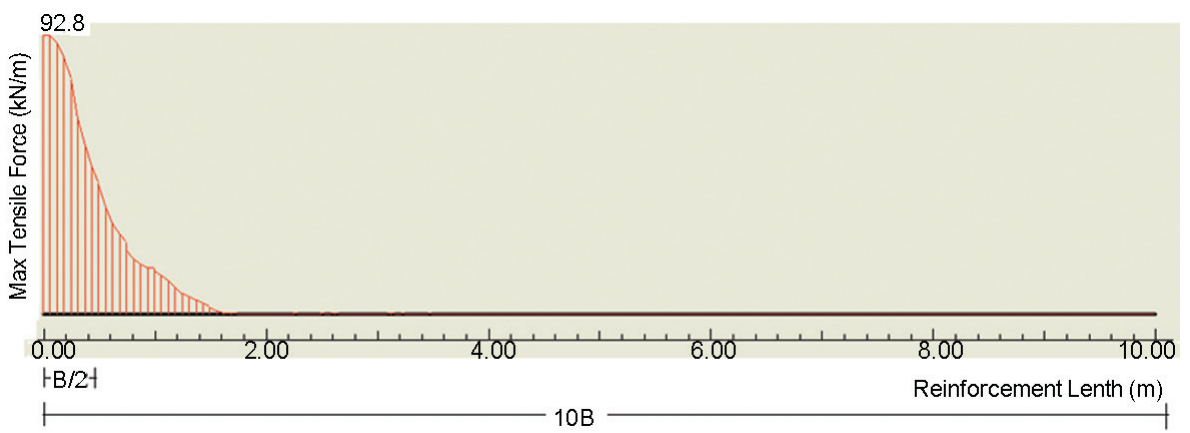

b)

Fig. 3. Reinforcement axial forces for $\mathrm{B} / 2=0.5 \mathrm{~m}, h_{1}=0.75 \mathrm{~m}, \phi_{1}=39^{\circ}$ on $\phi_{2}=36^{\circ}$ : a) $\left.\mathrm{L} / 2=0.5 \mathrm{~m}, \mathrm{~b}\right) \mathrm{L} / 2=10 \mathrm{~m}$

The depth of the reinforcement to width of foundation ratio $(h / \mathrm{B})$, the foundation width $(\mathrm{B})$, the internal friction angle of the denser upper layer $(\phi)$ and length of the reinforcement to width of foundation ratio (L/B) were chosen as the independent parameters. The following relation was obtained from the multiple regression analysis:

$$
T=110 h / \mathrm{B}+68.8 \mathrm{~B}+5.07 \phi+8.05 \mathrm{~L} / \mathrm{B} 267 .
$$

In this equation $T$ is the tensile stress in the reinforcement, $h$ is the distance of the reinforcement from the base of footing, $\mathrm{B}$ is the footing width, $\mathrm{f}$ is the internal friction angle of the upper strata, $\mathrm{L}$ is the reinforcement length. In the regression analyses the $\mathrm{L} / \mathrm{B}$ ratio was chosen as 1 for the reinforcement that has the same length as the

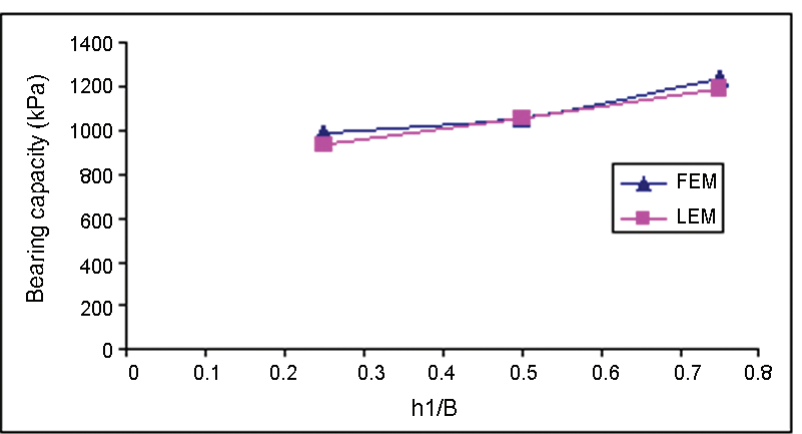

Fig. 4. Comparison of bearing capacity values with models $\left(\mathrm{B}=2 \mathrm{~m}, \mathrm{~L}=\mathrm{B}\right.$ and $\phi_{1}=34^{\circ}$ on $\left.\phi_{2}=31^{\circ}\right)$ footing. For the case of the long reinforcement the L/B ratio was taken as 2 .

The regression coefficient of equation 26 was found as $\mathrm{R}=0.97$. This shows that there is a good correlation. The significance of every coefficient was investigated as well and as can be seen from the $\mathrm{t}$ and $\mathrm{P}$ distribution values given in Table 6 . It can be stated that the relation between each individual parameter and the tensile stress $(T)$ is significant.

The bearing capacity values of reinforced soil obtained from Finite Element analyses and the Limit1 Equilibrium method proposed in this paper is compared in Figure 6. In this Figure, $q_{1 \text { max }}$ and $q_{1 \text { min }}$ are the bearing capacity values of FEM and LEM for $\mathrm{L}=\mathrm{B}$ with tensile load of reinforcement taken as $T$ and $T \cos \alpha A_{2}$,

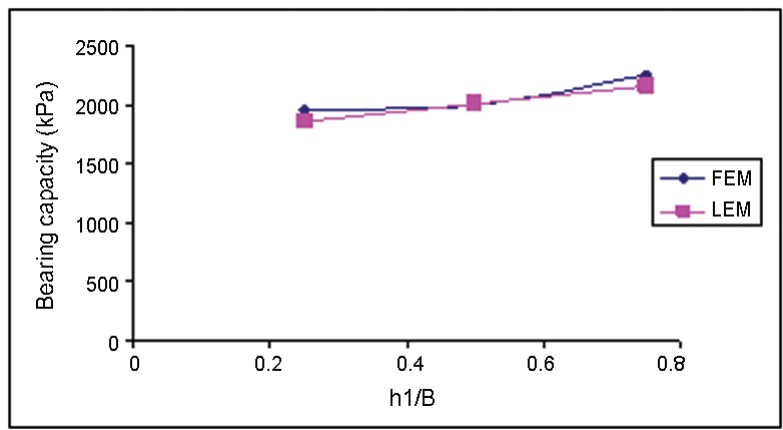

Fig. 5. Comparison of bearing capacity values with models $\left(\mathrm{B}=2 \mathrm{~m}, \mathrm{~L}=\mathrm{B}\right.$ and $\phi_{1}=39^{\circ}$ on $\phi_{2}=36^{\circ}$ 
Table 6. Results of multiple regression analysis

\begin{tabular}{lcccc}
\hline & Coefficients & $\begin{array}{c}\text { Standard } \\
\text { error }\end{array}$ & t Stat & P-value \\
\hline Variable 1 $(h / \mathrm{B})$ & 109.9 & 14.77 & 7.44 & $2.22 \mathrm{E}-08$ \\
\hline Variable 2 $(\mathrm{B})$ & 68.83 & 3.69 & 18.6 & $2.13 \mathrm{E}-18$ \\
\hline Variable 3 $(\phi)$ & 5.075 & 1.206 & 4.21 & $2.05 \mathrm{E}-4$ \\
\hline Variable 4 $(\mathrm{L})$ & 8.055 & 2.01 & 4.01 & $3.58 \mathrm{E}-4$ \\
\hline Intercept & -267.6 & 45.6 & -5.86 & $1.80 \mathrm{E}-06$ \\
\hline
\end{tabular}

respectively. $q_{2 \max }$ and $q_{2 \min }$ are the bearing capacity values of FEM and LEM for $\mathrm{L}=20 \mathrm{~B}$ with tensile load of reinforcement taken as $T$ and $T \cos \alpha A_{2}$, respectively. A solid line was drawn in these graphs indicating equal values of LE and FEM results. As can be seen from this figure the new limit equilibrium approach gives values very close to the bearing capacities obtained from Finite Element solutions. The differences are very small and within acceptable limits in civil engineering practice.

\section{Worked example}

A strip foundation of width $\mathrm{B}=3 \mathrm{~m}$ rests on a reinforced two layered soil. The top sand layer has a thickness of $h=1.5 \mathrm{~m}$, underlain by a deep bed of second sand soil. The friction angle of the fill (top) sand layer is $\phi_{1}=39^{\circ}$ and the unit weigh is $\gamma_{1}=20.9 \mathrm{kN} / \mathrm{m}^{2}$. The friction angle of the natural (bottom) sand is $\phi_{2}=36^{\circ}$ and the unit weigh is $\gamma_{2}=20.5 \mathrm{kN} / \mathrm{m}^{2}$. Friction angles along surface between active and passive zones are taken as $\delta_{1}=17^{\circ}$ and $\delta_{2}=$ $15^{\circ}$. The surcharge on the soil is taken as $q=25 \mathrm{kN} / \mathrm{m}^{2}$. The reinforcement is placed between the two sand layers. The bearing capacity is calculated for a reinforcement length equal to the foundation width $(\mathrm{L}=\mathrm{B}=3 \mathrm{~m})$. The calculation of the bearing capacity of reinforced soil with the new proposed formulation is given below.

Firstly, the maximum tensile force in the reinforcement is calculated by making use of Eqn (26):

$$
\begin{gathered}
T_{1}=110\left(\frac{1.5}{3}\right)+68.8 * 3+5.07 * 39+8.05 *(1)-267 . \\
T_{1}=200 \mathrm{kN} / \mathrm{m} .
\end{gathered}
$$

Bearing capacity factors are calculated considering $\left(T_{f}\right)_{\max }=T,(\beta=0) . \mathrm{N}_{q}$ and $N_{\gamma}$ values are founded from Eqns (17) and (25) as 39.5 and 60 , respectively. The equivalent unit weight of soil is found as $20.7 \mathrm{kN} / \mathrm{m}^{3}$. Ultimate bearing capacity of reinforced soil is found by making use of Eqn (12) and the ultimate bearing capacity is found as $2845 \mathrm{kPa}$.

For $\left(T_{f}\right)_{\min }=T^{*} \cos \alpha_{A 2}\left(\beta=\alpha_{A 2}\right)$ the bearing capacity factors are calculated as $N_{q}=36$ and $N_{\gamma}=57$. Ultimate bearing capacity for $\left(T_{f}\right)_{\text {min }}$ is equal to $2676 \mathrm{kPa}$. The bearing capacity computed by using Finite Element Method as $2946 \mathrm{kPa}$. Therefore, it can be concluded that the values of bearing capacity of the reinforced foundation using the method proposed in this paper match the results of the Finite Element analyses well. For the same example without any reinforcement the bearing capac-

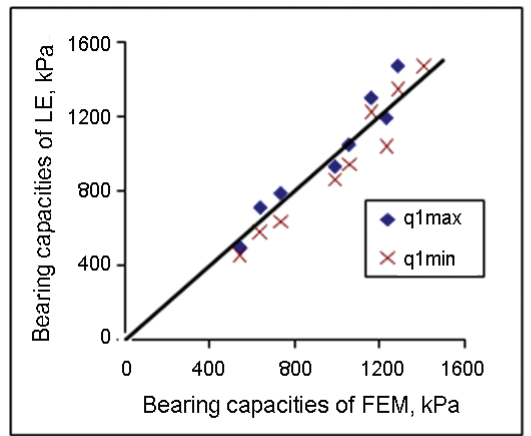

a)

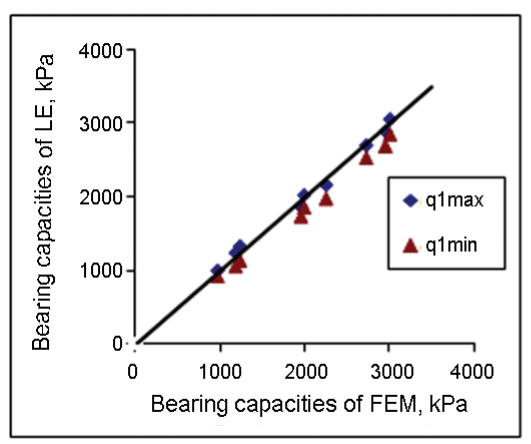

c)

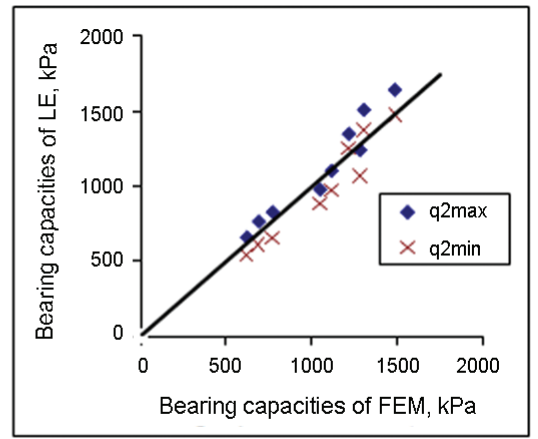

b)

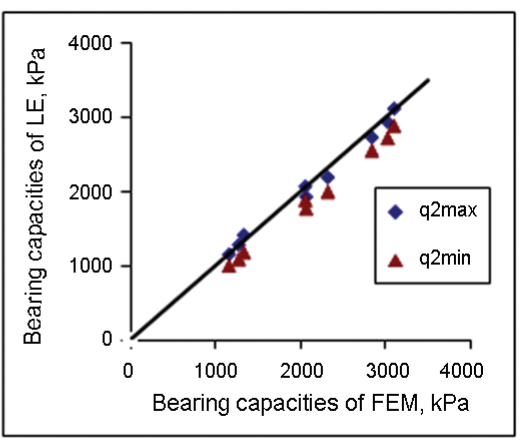

d)

Fig. 6. Comparisons of bearing capacity obtained from FEM and the New Limit Equilibrium Approach: a) L= B and b) $\mathrm{L} / \mathrm{B}=2$ for $\phi_{1}=34^{\circ}$ on $\phi_{2}=31^{\circ}$, c) $\mathrm{L}=\mathrm{B}$ and d) $\mathrm{L} / \mathrm{B}=2$ for $\phi_{1}=39^{\circ}$ on $\phi_{2}=36^{\circ}$ 
ity from Finite Element analysis was found as $2514 \mathrm{kPa}$. This indicates that with the reinforcement approximately $17 \%$ improvement in bearing capacity was obtained.

\section{Conclusions}

In this paper a limit equilibrium method is developed for calculating the bearing capacity factors of strip foundations on a two-layered reinforced granular soil. New formulations for the ultimate bearing capacity factors $N_{q}$ and $N_{\gamma}$ were derived for two layered soils which were reinforced with a single reinforcement layer. The results obtained were compared with the results obtained from Finite Element analysis. The ultimate bearing capacities of reinforced soils for two extreme geosynthetic lengths were considered. One extreme is the case where the reinforcement length is equal to the footing width $(\mathrm{L}=\mathrm{B})$. The second extreme is that a very long reinforcement is used. When results are evaluated it was determined that for $L \geq 4 B$, the case of long reinforcement is valid. The results obtained from the new proposed formulation were compared to the Finite Element analysis results. As a result it can be stated that closed form solution and the finite element analysis results are in agreement with each other. Therefore, it can be stated that the bearing capacities of footings on a two layered soil reinforced with one layered reinforcement can be estimated with the new limit equilibrium approach successfully.

In the limit equilibrium analysis proposed in this paper, the tensile force mobilized in the geosynthetic reinforcement is determined by the correlation formula given in Eqn (26).

When the bearing capacities of footings with short and long reinforcements are compared, it can be seen that the bearing capacities determined for the long reinforcement is 1.23 times higher than the bearing capacity obtained for the short reinforcement length $(\mathrm{L}=\mathrm{B})$. However, an improvement is also obtained for a reinforcement that is only as wide as the footing itself.

Considering the many results reported in the literature, it can be stated that no difference occurs for a reinforcement length above $\mathrm{L}=4 \mathrm{~B}$. Also the tensile force distribution obtained in this study verifies this statement. Therefore, it can be stated that the bearing capacities obtained for long reinforcement is valid for $\mathrm{L} \geq 4 \mathrm{~B}$ and for shorter reinforcement lengths an interpolation can be made between the two extreme conditions.

\section{Acknowledgements}

The authors thank the Scientific and Technical Research Council of Turkey (TUBITAK) for doctorate scholarship.

\section{References}

Abu-Farsakh, M.; Gu, J.; Voyiadjis, G.; Chen, Q. 2012. Finite element parametric study on the performance of strip footings on reinforced crushed limestone over embankment soil, Electronic Journal of Geotechnical Engineering 17 Bundle F: 723-742.
Adams, M. T.; Collin, J. G. 1997. Large model spread footing load tests on geosynthetic reinforced soil foundations, Journal of Geotechnical and Geoenvironmental Engineering ASCE 123(1): 66-72.

http://dx.doi.org/10.1061/(ASCE)1090-0241(1997) $123: 1(66)$

Binquet, J.; Lee, K. L. 1975a. Bearing capacity tests on reinforced earth slabs, Journal of Geotechnical Engineering Division ASCE 101(GT12): 1241-1255.

Binquet, J.; Lee, K. L. 1975b. Bearing capacity analysis of reinforced earth slabs, Journal of Geotechnical Engineering Division ASCE 101(GT12): 1257-1276.

Chen, Q. 2007. An experimental study on characteristics and behavior of reinforced soil foundation. $\mathrm{PhD}$ dissertation. Louisiana State University, Baton Rouge, USA.

Dey, A. 2010. Bearing capacity of reinforced foundations: Statistical approach and sensitivity analysis, Procedia Social and Behavioral Sciences 2: 7642-7643. http://dx.doi.org/10.1016/j.sbspro.2010.05.157

El Sawwaf, M. A. 2007. Behavior of strip footing on geogridreinforced sand over a soft clay slope, Geotextiles and Geomembranes 25(1): 50-60. http://dx.doi.org/10.1016/j.geotexmem.2006.06.001

El Sawwaf, M.; Nazir, A. K. 2010. Behavior of repeatedly loaded rectangular footings resting on reinforced sand, Alexandria Engineering Journal 49: 349-356.

Ghazavi, M.; Eghbali, A. H. 2008. A simple limit equilibrium approach for calculation of ultimate bearing capacity of shallow foundations on two-layered granular soils, Geotechnical and Geological Engineering 26(5): 535-542. http://dx.doi.org/10.1007/s10706-008-9187-2

$\mathrm{Gu}$, J. 2011. Computational modeling of geogrid reinforced soil foundation and geogrid reinforced base in flexible pavement. PhD Dissertation. Department of Civil Engineering and Environmental Engineering, University of Louisiana State University, Baton Rouge, USA.

Huang, C. C.; Tatsuoka, F. 1990. Bearing capacity of reinforced horizontal sandy ground, Geotextiles and Geomembranes 9: 51-82. http://dx.doi.org/10.1016/0266-1144(90)90005-W

Huang, C. C.; Meng, F. Y. 1997. Deep-footing and wide-slab effects in reinforced sandy ground, Journal of Geotechnical and Geoenvironmental Engineering ASCE 123(1): 30-36.

Kumar, A.; Saran, S. 2003. Bearing capacity of rectangular footing on reinforced soil, Geotechnical and Geological Engineering 21(3): 201-224. http://dx.doi.org/10.1023/A:1024927810216

Lambe, T. W.; Whitman, R. V. 1969. Soil mechanics. New York: John Wiley and Sons. 553 p.

Lavasan, A. A.; Ghazavi, M. 2012. Behavior of closely spaced square and circular footings on reinforced sand, Soils and Foundations 52(1): 160-167. http://dx.doi.org/10.1016/j.sandf.2012.01.006

Madhavi, L. G.; Somwanshi, A. 2009. Bearing capacity of square footings on geosynthetic reinforced sand, Geotextiles and Geomembranes 27(4): 281-294.

Michalowski, R. L. 1998. Limit analysis in stability calculations of reinforced soil structures, Geotextiles and Geomembranes 16(6): 311-331.

Michalowski, R. L. 2004. Limit loads on reinforced foundation soils, Journal of Geotechnical and Geoenvironmental Engineering ASCE 130(4): 381-390.

Nogueira, C. L.; Oliveira, R. R. V.; Zornberg, J. G.; Azevedo, R. F. 2008. FE prediction of bearing capacity of reinforced soil under plane strain condition, in The First Pan American Geosynthetics Conference \& Exhibition, 2-5 March 2008, Cancun, Mexico, 1391-1400. 
Patra, C. R.; Das, B. M.; Bhoi, M.; Shin, E. C. 2006. Eccentrically loaded strip foundation on geogrid-reinforced sand, Geotextiles and Geomembranes 24(4): 254-259. http://dx.doi.org/10.1016/j.geotexmem.2005.12.001

Richards, R.; Elms, D. G.; Budhu, M. 1993. Seismic bearing capacity and settlements of foundations, Journal of Geotechnical Engineering ASCE 119(4): 662-674.

Schmertmann, J. H.; Brown, P. R.; Hartman, J. P. 1978. Improved strain influence factor diagrams, Journal of the Geotechnical Engineering Division ASCE 104(8): 1131-1135.

Sharma, R.; Chen, Q.; Abu-Farsakh, M.; Yoon, S. 2009. Analytical modeling of geogrid reinforced soil foundation, Geotextiles and Geomembranes 27(1): 63-72. http://dx.doi.org/10.1016/j.geotexmem.2008.07.002

Terzaghi, K. 1943. Theoretical soil mechanics. New York: John Wiley and Sons. $510 \mathrm{p}$. http://dx.doi.org/10.1002/9780470172766
Wayne, M. H.; Han, J.; Akins, K. 1998. The design of geosynthetic reinforced foundations, in Proceeding of ASCE'S 1998 Annual Convention \& Exposition, ASCE Geotechnical Special Publication 76: 1-18.

Tafreshi, S. N. M.; Dawson, A. R. 2010. Comparison of bearing capacity of a strip footing on sand with geocell and with planar forms of geotextile reinforcement, Geotextiles and Geomembranes 28(1): 72-84. http://dx.doi.org/10.1016/j.geotexmem.2009.09.003

Yamamoto, K.; Otani, J. 2002. Bearing capacity and failure mechanism of reinforced foundations based on rigid-plastic finite element formulation, Geotextiles and Geomembranes 20(6): 367-393.

Yetimoglu, T.; Wu, J. T. H.; Saglamer, A. 1994. Bearing capacity of rectangular footings on geogrid-reinforced sand, Journal of Geotechnical Engineering ASCE 120(12): 2083-2099.

http://dx.doi.org/10.1061/(ASCE)0733-9410(1994)120:12(2083)

Elif CICEK. Dr, Received her PhD degree in June 2011 in Civil Engineering at Ataturk University, Turkey. She took many courses from Istanbul Technical University and Marmara University, Turkey. Her thesis' numerical and experimental studies were conducted at Bogazici University, Turkey was supported with doctorate scholarship by Scientific and Technical Research Council of Turkey (TUBITAK). Her research interests include effects of geosynthetic reinforcements under foundations, pressure distribution of soils, slope stability, earthquake, limit equilibrium approaches and numerical methods.

Erol GULER. Professor of Civil Engineering at Bogazici University, Istanbul, Turkey. He is IGS Council member. He founded the IGS Turkish Chapter in 2001 and served as its president until 2005, and was re-elected as President again in 2011. He represents Turkish Standards Institute (TSE) at the International Standards Organization (ISO) and the European Committee for Standardisation (CEN). He is Convener of the WG2 of the ISO TC221 (Technical Committee on geosynthetics) and is also the Convener of the WG2 of the CEN TC189 (Technical Committee on geosynthetics). He is currently an international member of the USA TRB Committee on Geosynthetics. His research subjects are mainly geosynthetics and specifically geosynthetic reinforcement and liner systems. Has vast experience in design of foundations, deep excavations, landslide mitigation and site investigations. 